\title{
A Context-Aware Mashup Integration Guideline for Enterprise 2.0
}

\author{
Gerald Bader, Amin Anjomshoaa, and A Min Tjoa \\ Institute of Software Technology and Interactive Systems \\ Vienna University of Technology, \\ Favoritenstraße 9-11/188, A-1040, Vienna, Austria \\ gbader@gmx.at, \{anjomshoaa, amin\}@ifs.tuwien.ac.at
}

\begin{abstract}
Recent advances in Internet Computing have changed the outlook of business and enterprise cooperation models. Many companies have started to leverage their services in order to move toward Enterprise 2.0. In this regard enabling technologies such as Mashups play a significant role to shift away from traditional information management environments towards dynamic and collaborative systems.

In this paper, different business aspects of Mashup architecture in enterprise use-cases will be explored and the SWISHGUIDE-framework for capturing the needs and readiness factors of target organization will be introduced. The proposed SWISHGUIDE framework provides a decision-making guideline for transition from traditional information management systems to a successful Enterprise Mashup architecture.
\end{abstract}

Keywords: Enterprise 2.0, Mashup, SOA, Migration, Business Services, Crowd Sourcing, Social Networks, Web 2.0.

\section{Introduction}

The business today needs fast, accurate and reliable information resources in order to make real-time and effective decisions; however the existing business solutions are not flexible enough to fulfill the requirements of future business and get adapted to dynamic business changes. In today's highly competitive marketplace, businesses need to differentiate themselves from the competitors, connect and engage customers and potential customers, get their brand recognized, and sell their products and services [1].

In this context, the Enterprise 2.0 is introduced as a system of web-based technologies that provide rapid and agile collaboration, information sharing, emergence, and integration capabilities in the extended enterprise [2]. The need for Enterprise 2.0 is forced by technology trends such as Web 2.0 [3], crowd computing, and cloud computing combined with the business trends such as consolidation and knowledge management [4].

Enterprise 2.0 describes how organizations can benefit from such new technologies, how they can implement it, and what organizational changes and impacts need to be 
considered. Enterprise 2.0 is also considered to benefit from Web 2.0 paradigm and its relevant technologies for sake of business purposes [5]. From another perspective, the Enterprise 2.0 can be at its simplest level defined as the extension of traditional organizations by social platforms to fulfill the effective collaboration and information sharing requirements. In order to have an all-embracing Enterprise 2.0 landscape, technology added-values such as blogs, RSS feeds, wikis, enterprise search and Mashup solutions need to be considered [6,7].

On the other hand, companies have to realize that Enterprise 2.0 will come anyway [8] and the change from a traditionally working and acting company to Enterprise 2.0 is a time consuming process which cannot be done in course of a few months. Especially changing the mindset and cultural issues is a long lengthy process [9]. In short the practice of management is changing from strict rules and fixed processes to a more liberate and open information space in modern cooperation models [10].

It is also important to note that the Enterprise 2.0 can only be a success story by involving and training the employees and information workers to understand how to use such tools and products and how to create the most and best outcome from it.

In this paper we exploit Enterprise Mashups as an enabling technology to get a step closer to Enterprise 2.0 goals. We will also explore the shift from traditional IT architectures to Enterprise 2.0 from different perspectives. The main contribution of this paper is the introduction of a context-aware Mashup integration guideline -called SWISHGUIDE- for assessing the readiness of a generic organization for undertaking Enterprise Mashups. In this context the corresponding opportunities and risks of the proposed solution will be discussed in details.

\section{Enterprise Mashups}

The organizations of today are confronted by business pressures to decrease costs, reduce workforce and transform their business from an internally focused organization into a service oriented and customer centric organization, which target the need of their customers. Therefore organizations have to deal with different knowledge domains and bring them together, which in turn means also dealing with many common business process concepts and architectures [11].

SOA (Service Oriented Architecture) and RIA (Rich Internet Applications) are leading the standardized access to business functionality and data with desktop-like interaction over the Web. But for information workers it is difficult to use these new technologies to improve their daily tasks. Furthermore SOA-enabled companies are now facing difficulties to manage and to provide information on how the services interact and whether they are used in the right way [12]. Mashups enable users to get access to data sources through SOA by a user-driven process with short development cycles.

Enterprise Mashups (also known as Business Mashups) can be defined as usercreated applications that combine internal and external resources and publish the results in appropriate way on enterprise portals [13]. Enterprise Mashups have a strong focus on data and service integration, merging, and distribution of content. Unlike the Data-Mashups and Consumer-Mashups, Enterprise Mashups are used in business use-cases for more fundamental, complex and sometimes business-critical 
tasks. Therefore topics such as trust \& security, governance and stability play an important role for this group of Mashups and need a closer examination [14,15].

In order to provide a Mashup transition guideline for organizations, an in-depth understanding of the Mashup patterns is required. Some of these patterns can be summarized as follows [16]:

- Self-service Pattern: Business users create Mashups on their own to handle business needs. Unlike traditional organizations where the solutions are solely created and managed by the IT department, business users with average IT skills can also take the lead in creating the required solutions.

- Source Integration Pattern: Companies can integrate both internal and external resources for certain business processes or decision-making. In its simplest form, the organizations can present their backend information as services. These can be used to generate additional business value via information transparency and reaching more end-users.

- Share \& Reuse Pattern: The Mashup solutions provide good potential for solution sharing and solution reuse. This aspect of Mashup solutions can save lots of time for creating new solutions provided that the proper documentation and service governance is in place. Many companies are now thinking about the benefits of public and private clouds that host the shared services and data resources.

- Democratization of Data: The Mashup solution can also be used for encapsulating the business logic and making the data accessible via data feeds and APIs. In other words, the data which was previously limited to one department can now be freely used by other authorized people to make useful ad-hoc solutions.

\section{Need-Readiness Matrix for Enterprise Mashups}

In order to guaranty a smooth and reliable transition from traditional architecture to Enterprise Mashup landscape, the technical, organizational and social aspects should be studied carefully and considered in all transition phases. Such analysis can be conducted in two directions, namely: Readiness of target organization for integrating Mashup and Organizational Need for Mashups.

The Mashup Readiness aims to estimate the acceptance level of Enterprise Mashup solutions in the target company and covers both technical-readiness and peoplereadiness aspects. On the other hand, the "Need for Mashups" studies the business needs and requirements that can be addressed by Enterprise Mashups. After an appropriate analysis of these two dimensions the decision makers will have a clearer outlook of business opportunities and can evaluate the balance between benefits and the required transition efforts according to the readiness factors.

The correlation between Mashup Readiness and Need for Mashup, can be summarized in a Readiness-Need estimation matrix as shown in Table 1. 
Table 1. Readiness-Need estimation Matrix for Enterprise Mashups implementation

\begin{tabular}{|l|l|l|}
\hline & \multicolumn{1}{|c|}{ Low Need } & \multicolumn{1}{|c|}{ High Need } \\
\hline Ready & $\begin{array}{l}\text { Target organization is } \\
\text { fulfilling the technical, } \\
\text { organizational and social } \\
\text { prerequisites of Mashup } \\
\text { undertaking but the use- } \\
\text { cases of target organization } \\
\text { cannot benefit from Mashup } \\
\text { features to a big extent. }\end{array}$ & $\begin{array}{l}\text { The } \\
\text { required IT infrastructure and a } \\
\text { broad spectrum of support from } \\
\text { readiness coupled with the high } \\
\text { business need offer the best } \\
\text { condition for a successful and } \\
\text { valuable enterprise Mashup } \\
\text { migration. }\end{array}$ \\
\hline Not Ready & $\begin{array}{l}\text { The company does not fulfill } \\
\text { the prerequisites sufficiently } \\
\text { neither there seems to be a } \\
\text { need for it. Therefore an } \\
\text { implementation is not } \\
\text { recommendable. }\end{array}$ & $\begin{array}{l}\text { The organization is not owning } \\
\text { the required IT infrastructure or } \\
\text { do not have a broad spectrum } \\
\text { of support from the } \\
\text { stakeholders. Through the high } \\
\text { need for Mashups solutions it is } \\
\text { recommendable to increase the } \\
\text { readiness by certain initiatives } \\
\text { before starting a Mashup } \\
\text { undertaking. }\end{array}$ \\
\hline
\end{tabular}

Obviously the implementation of an Enterprise Mashup solution is very relevant for the top right quarter of this matrix, where on one hand the company is ready to realize the new architecture, and on the other hand the business use-cases demand a Mashup-based approach.

Although the areas of the Readiness-Need matrix have a simple and straightforward definition, but the main challenge remains, to find the proper location of a given organization in this matrix.

In the next chapters we will introduce some indicators in order to position the target organization in the Readiness-Need matrix during the transition phases. For this purpose we will first introduce SWISHGUIDE which facilitates study of target organization based on a unique approach and then define the required methods to assess the readiness and business need indicators.

\section{SWISHGUIDE}

SWISHGUIDE is the abbreviation for the main advantages that a business can gain from utilization of Mashup-based solutions. The SWISHGUIDE factors will be used to assess the Mashup-readiness and business needs of target organizations. These items are grouped in three main categories: business aspects, facility aspects and social aspects. The business category contains some required factors in order to increase the efficiency and generate business added-value for target organization. 
The facility aspects focus on more effective management and sharing of information resources and finally the social category describes the benefits of Mashup solutions for end-users and how they can be used to promote social solutions.

Figure 1 demonstrates the SWISHGUIDE categories and the relevant factors of each category. In the rest of this section, the SWISHGUDE factors will be introduced in more detail.

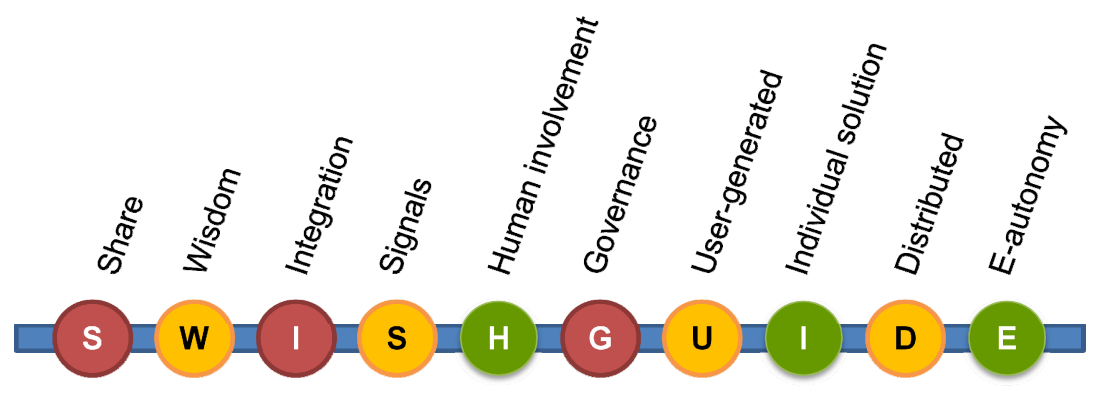

Fig. 1. SWISHGUIDE

\subsection{Business Aspects}

Enterprise Mashups have a strong focus on data and service integration, merging and distribution of content. One of the major problems in modern business is that many vital processes between stakeholders are to a large extent managed manually and require human intervention for tasks such as recognition, extraction, and reformatting. These manual processes may hamper the effective and timely interoperation between stakeholders. Enterprise Mashups can change the situation by automating parts of such processes by liberating the business users from uninteresting and monotonous tasks and letting them focus on their business solutions.

In this context the major benefits of Mashups for business can be described as shared wisdom, user-generated resources, information alerts (signals) and finally information distribution. These factors will be explained in more details below.

- Wisdom: The plethora of business user interactions in the business field and the domain knowledge of experts is a precious resource that can be shared with community in order to facilitate more effective decision making processes. Knowledge, as the most important asset of companies, needs to be captured and transferred to the right employees at the right time, via appropriate channel, and in an understandable format. The Mashups may support the process of creating collective wisdom and sharing the expert solutions by capturing and documenting reusable components and information resources.

- User-Generated: The business users, who are not necessarily IT experts, usually need to access the information resources and adopt them according to their specific requirements in their daily tasks [17]. Most of such micro-solutions fall under the long tail of user requirements and are not covered by standard business solutions. 
- Signals: The business users and especially managers need to make decisions based on actual and accurate data. Companies often struggle to keep their decision makers up to date regarding data resources and processes. Mashups have big potential for more efficient and simpler signaling methods among systems and users to keep the business users automatically and instantly updated about data resources and processes.

- Distributed: Through the heterogeneous IT landscape and complex business processes the interaction of IT systems is a challenging issue. Many business processes rely on an intensive interaction between IT systems in order to fulfill their business requirements and have to interact with partners, suppliers or customers in a technically sophisticated, timely and competitive manner.

\subsection{Facility Aspects}

Besides the business aspects, companies can also benefit from IT services of Mashups for improving the quality of knowledge management in their organization. In a Mashup-based business environment the role of IT departments is changing from software providers to services administrators who should take care of security and governance aspects of available services. Such services range from complex proprietary services to simple directories for existing and user-generated services.

As such, business users have the freedom to assemble their applications for their daily challenges from exposed services in a productive way. By applying the appropriate governance policies such as security, versioning, and legislation the usergenerated solutions will be readily available for reuse in other business solutions.

In this section three main aspects of Enterprise Mashups namely sharing, integration, and governance for supporting the IT facilities will be introduced.

- Share: Neglecting the effective sharing of the business information in a modern business may cost extra time and money. In order to address this issue, companies should establish instant and trustable communication channels. Today knowledge sharing is done via traditional methods such as email, phone, etc and rarely through a central knowledge management system. Therefore only a small group of people have access to certain knowledge. Mashups may provide enhanced sharing and reusing of business knowledge and information via:

- organization-wide business taxonomies

- uniform information query and retrieval and

- addressable data resources and information feeds

- Integration: The fast changing market, demands continuous change in the companies' business relationships such as changing partners, new suppliers, new customers, etc. The dynamic of relationships should be also reflected in the underlying systems and processes, which is one of the most challenging issues that companies are facing today. In order to adjust their business to follow impulse market changes, companies need to adopt existing solutions and processes instantly by integration of new resources. Mashup solutions can facilitate the integration of internal and external resources via APIs, web-services, feeds, etc. 
- Governance: Without governance a project will fail, company processes end up in chaos and the IT landscape will get out of control. Governance is the managementand structural backbone in organizations to define clear roles and responsibilities and to ensure a stable and trustworthy environment [18]. Mashup solutions can bring more effective governance of services, solutions and data via

- a centralized pool of annotated data resources and services

- a uniform security schema and roles

\subsection{Social Aspects}

Finally the social aspects of SWISHGUIDE, focus on the inherited features from Web 2.0, namely Human involvement, Individual solutions, and E-autonomy. In the rest of this section, the social aspects are presented with more details.

- Human Involvement: "Mastery over life skills, curiosity and learning, social support, and shared goals were keys to the survival and prosperity of early humans. If you think of humans as a social species then it makes sense to think of us as tuned to do things to help the group" [19].As the world changes more and more towards knowledge-based societies, companies and their employees need to change into knowledge workers. But knowledge which is not shared is lost. For example, if an employee leaves the company also his knowledge will leave the company. The key for better knowledge management is the exchange of knowledge between users. Mashups empower users to capture the knowledge of employees and share their expertise which leads to better team-working.

- Individual Solutions: In order to undertake daily tasks, users usually invent their own personalized solutions parallel to company's standard solutions which are usually led to manual and duplicated work. Since these solutions are a matter of taste, IT departments cannot support users with individual solutions. With Mashups business users can easily create individual solutions based on personal preferences and specific needs. Such solution can be also filtered and ranked based on some quality indicators (assessed by IT department, or user community) and reused in other business use-cases.

- E-autonomy: It is already a known fact that generally software solutions cannot cover the long tail of requirements [20] and the standard solutions of IT departments only address around $20 \%$ of the user requirements. Since IT departments are usually overloaded with user requirements, the business departments often start their own initiatives to solve their specific issues via ordering added-value solutions which may lead to data silos, and heterogeneous IT landscapes. With the self-service and easy-to-use approach of Mashups everybody can create their own solutions and IT departments are then responsible to provide holistic advanced services such as security, versioning, legislation, etc.

\section{$5 \quad$ Organization Readiness for Mashup Migration}

In order to start with a Mashup undertaking, the first step is to identify the readiness of the candidate organization by taking the current IT state and people-support into 
consideration. From technical perspective we need to assess the infrastructure profile of the target company, which includes different aspects such as existing software, hardware, and frameworks. This result should be combined with People Readiness to obtain the overall readiness of the target company. The following sections provide more details on assessing the readiness factors.

\subsection{Infrastructure Readiness}

The existence of a proper infrastructure and supporting framework in an organization can guarantee the success of Mashup implementation to a large extent. Before starting a Mashup transition, the relevant tools, services and infrastructure should be captured and documented. Without any doubt, the SOA framework and the SOA-enabled tools play an important role in Mashup transition and companies who have already employed SOA in their software landscape will have a better initial position for a Mashup undertaking. Likewise, a Mashup implementation can benefit greatly from well-established trust, security and knowledge management models.

In order to capture and analyze the infrastructure readiness of an organization, a survey of the current state, needs to be done in order to answer questions such as:

- Is there a broadband internet connection available?

- Are processes web-accessible and addressable?

- Are services web-accessible and addressable?

- Are data resources web-accessible and addressable?

- Are your applications accessible via dedicated APIs?

- Is your business logic accessible via dedicated APIs?

- Are there any search mechanisms in place for finding resources?

- Is there a SOA architecture in place?

- Are there security guidelines and rules for new technologies like Web 2.0 and Cloud Computing?

The designed survey, based on the above questions, will be answered by IT experts of the target organization. The result is summarized as a total score, which indicates the infrastructure readiness and will be later on used in combination with peoplereadiness to assess the organization readiness for a Mashup undertaking.

The infrastructure readiness is just one side of the coin for a successful Mashup transition; the people readiness plays also a significant role. The reason for this, lies on the fact that in a Mashup-based environment some traditional responsibilities of IT-departments will be carried out by the end-users. As a result the end-user's acknowledgment and effective use of new frameworks is of great importance. In the next section, the people readiness is explained in more details and a method for quantifying its state will be presented.

\subsection{People Readiness}

Most of the time, IT undertakings are seen and planned only as technical projects. In such projects, architecture definition, tool evaluation or data integration are the center of attention and the social aspects do not receive appropriate emphasis. However, the 
success of a project is strongly dependent upon the involved people and the stakeholders. Therefore the mindset of the people adaptability to change, their expectations and fears, and also their needs and requirements have to be considered [21].

This issue gets even more important in case of a Mashup undertaking, because the Mashup solution by definition is taking benefit from user-generated solutions and collaboration. So if the end-users are already using Enterprise 2.0 technologies and are working and living in a collaborating and self-servicing environment the possibility of success is much greater, compared to traditional organizations.

In order to assess the people readiness in context of Mashup solutions, we will define the mapping between people readiness factors and the main Mashup benefits which were defined previously in the SWISHGUIDE. This mapping, which is shown in Table 2, provides the basis for measuring the people readiness of a target organization. As an example the "Web 2.0 literacy" factor which demonstrates the familiarity level of end-users with Web 2.0 platforms such as Twitter or Facebook can promote the Mashup environment via collective wisdom. Also the end-users, who are already used to notification mechanisms and modern communication channels of Web 2.0, can benefit more effectively from instant interactions in a Mashup environment.

Table 2. People readiness indicators

\begin{tabular}{|l|l|l|l|l|l|l|l|l|l|l|}
\hline People Readiness & S & W & I & S & H & G & U & I & D & E \\
\hline P1 - Web 2.0 literacy & & $\checkmark$ & & $\checkmark$ & & & & & & \\
\hline P2 - Micro-solution & & & & & $\checkmark$ & & $\checkmark$ & $\checkmark$ & & $\checkmark$ \\
\hline $\begin{array}{l}\text { P3 - Finding, Reformatting \& } \\
\text { Recreating }\end{array}$ & & & $\checkmark$ & $\checkmark$ & $\checkmark$ & & $\checkmark$ & $\checkmark$ & & $\checkmark$ \\
\hline P4 - Interoperability & & & $\checkmark$ & $\checkmark$ & & & & & $\checkmark$ & \\
\hline P5 : Broadcasting & $\checkmark$ & & & & $\checkmark$ & & $\checkmark$ & & & \\
\hline $\begin{array}{l}\text { P6 - Digital information } \\
\text { organization }\end{array}$ & $\checkmark$ & $\checkmark$ & & & $\checkmark$ & & & & & \\
\hline
\end{tabular}

This mapping concept will be extended to a questionnaire which will be answered by everybody in the target organization. It is important to note that the questionnaires can be customized according to organization requirements by expanding each factor and making appropriate questions that correspond to the given factor. Finally the results should be summarized and grouped according to introduced factors.

\section{Enterprise Need for Mashups}

As the company processes get more complex, business users need to accomplish more elaborated tasks. At the same time companies have to compete with other companies all over the world and adapt themselves to market changes. To stay competitive, they 
need flexible and agile IT solutions that can support dynamic business models. In this context, Mashup vendors promise improved collaboration, easier knowledge integration with lower costs and shorter development cycles. On the other hand the gain of various businesses from Mashup solution is different and determining the level of need is a challenging issue.

In this section, we will first define the need factors and then a method for evaluation the business needs, based on SWISHGUIDE, will be presented. The business need together with readiness factor of previous section, provides a solid basis for the decision about Mashup undertaking in a given organization.

Table 3. Business need indicators

\begin{tabular}{|l|l|l|l|l|l|l|l|l|l|l|}
\hline Business need & S & W & I & S & H & G & U & I & D & E \\
\hline B1- Customizations & & & & & $\checkmark$ & & $\checkmark$ & $\checkmark$ & & \\
\hline B2- Collaboration and reuse & $\checkmark$ & $\checkmark$ & & & $\checkmark$ & & $\checkmark$ & & & \\
\hline $\begin{array}{l}\text { B3 - Managed } \\
\text { Interdependency }\end{array}$ & $\checkmark$ & & $\checkmark$ & & & & & & $\checkmark$ & \\
\hline $\begin{array}{l}\text { B4- Reformatting and } \\
\text { recreating information }\end{array}$ & $\checkmark$ & & & & & & $\checkmark$ & $\checkmark$ & & $\checkmark$ \\
\hline B5- Service pool & & & & & & $\checkmark$ & $\checkmark$ & & & \\
\hline B6- Service taxonomy & $\checkmark$ & & $\checkmark$ & $\checkmark$ & & $\checkmark$ & & & & \\
\hline $\begin{array}{l}\text { B7- Security, trust and privacy } \\
\text { policies }\end{array}$ & & & & & & $\checkmark$ & & & & \\
\hline B8- Business Adoption & & $\checkmark$ & & $\checkmark$ & & & $\checkmark$ & $\checkmark$ & & $\checkmark$ \\
\hline B9- Interoperability & $\checkmark$ & & $\checkmark$ & $\checkmark$ & & & & & $\checkmark$ & \\
\hline B10- E-community interaction & $\checkmark$ & $\checkmark$ & $\checkmark$ & $\checkmark$ & & & & & $\checkmark$ & \\
\hline
\end{tabular}

Table 3 demonstrates the mapping between business need factors and the different Mashup benefits which are denoted as SWISHGUIDE. Similar to the readiness survey, a questionnaire will be designed according to the business need factors. Unlike the readiness questionnaire, the business need questionnaire is targeting only the business users.

During the questionnaire design, each business need item (items in Table 3) will correspond to one or more survey questions and finally the summarized result for each business need factor is calculated.

It is important to note that the Mashup need and successful Mashup implementation are two completely different points. The discussed approach should be considered as an input for decision makers and stakeholders regarding business needs. 
A simple questionnaire based on the defined indicators in Table 3 which should be answered by business users, looks as follows:

- B1: How extensive are the requests for customizations, new features, new reports or other temporal solutions?

- B2: How important is it for your organization to support collaborative use-cases by sharing and reuse of user-generated solutions?

- B3: In what extent are different departments of your organization dependent to each other (level of data exchange and process dependency)?

- B4: How heavily are manual tasks and self-programmed applications used in your organization?

- B5: How strong is the central governance of department services and usergenerated applications in your organization?

- B6: How well are your data resources documented and shared?

- B7: How good are the security, trust and privacy policies implemented in your organization?

- B8: How effectively is your business solution reacting to market changes?

- B9: How often do you run collaborative scenarios with internal and external actors?

- B10: Are you a member of a business online community?

\section{Discussion}

The proposed method will result in two values: those for "Mashup need" and "Mashup readiness". In addition we need also to define the borderlines of the needreadiness matrix that shape the final decision about the Mashup undertaking process. These borderlines should be decided by domain experts who are also familiar with Mashup solutions. Basically the "need borderline" is depending on the business branch of target organization and the "readiness borderline" should be set based on both branch and organization size. Generally a big enterprise with complex processes should have a higher readiness borderline. It means that such companies should deal with Mashup undertaking more conservatively and consider all aspects very carefully. On the other hand, in a small company (such as a reseller company) the readiness borderline can be set lower compared to the previous case. This is due to the fact that the risk and the business impact are usually lower compared to the case of a big enterprise.

After setting the borderlines, the Mashup undertaking decision can be made according to assessed values for need and readiness in the target organization. For instance, Figure 2 demonstrates the case where the target organization meets the readiness requirements but the business use-cases cannot fully benefit from Mashup solutions. So in this case, the recommendation of Mashup expert could be to keep an eye on business use-cases, and wait till the business needs are big enough for Mashup-based solutions. 


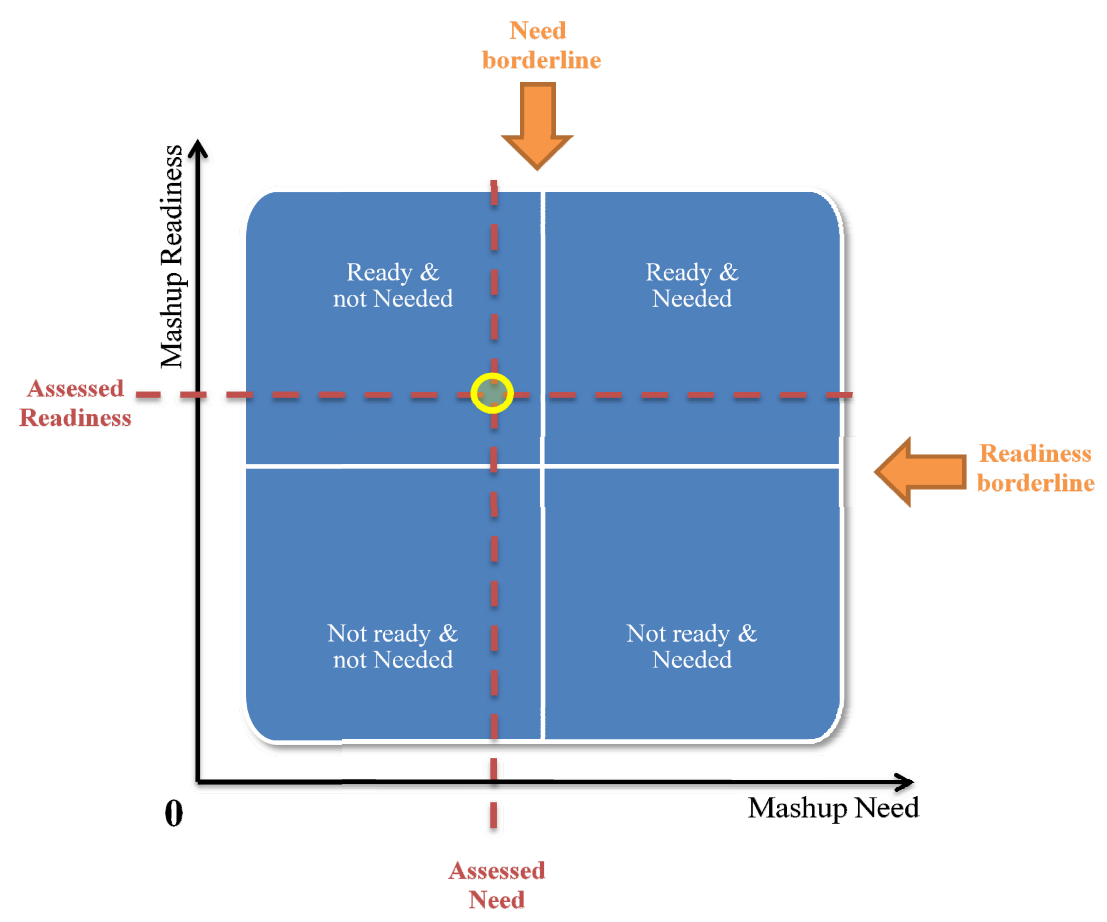

Fig. 2. Mashup undertaking decision based on Readiness-Need Matrix

\section{Evaluation}

For the evaluation and showing the usefulness of proposed guideline, an international industry and IT service-provider company was selected. This industry company has a strong international adjustment with an increasing need for collaboration and data sharing. Employees from all over the world work together in a project based environment. There are many different applications and systems for project-management, time sheeting, CRM etc used, which gives a good impression on the heterogeneity of the IT landscape.

The evaluation was accomplished following the implementation roadmap of the SWISHGUIDE Framework. The main input for the evaluation was received by interviews according the defined surveys. Based on the survey data the discussed implementation approach was verified.

The evaluation pointed out that the understanding for Mashup solutions and in general for Web 2.0 is still missing in companies. Companies are aware of Web 2.0 technologies like wikis, blogs or social networks, but they often do not know how to benefit from these technologies. Especially for the need survey it was clear that the people could not answer all the questions without additional clarification.

For this specific company, the need for enterprise Mashups was ascertainable; however, the missing fulfillment of the prerequisites and the insufficient readiness factors lead to a no-go decision based on the need-readiness matrix. 


\section{Conclusion}

Enterprise Mashups have gained momentum in modern business and in fulfilling the requirements of Enterprise 2.0; however, the decision about undertaking a Mashup solution in bigger organizations is a major strategic step that involves both objective and subjective decision making processes. Many technical and social factors should be considered before starting with a Mashup solution.

In this paper, the interrelationship between Mashup success factors and business needs are presented and the result is summarized as SWISHGUIDE framework. It is also important to note that the presented methodology is vendor-neutral and discusses an integration guideline to an ideal Mashup-based environment. The results of this study is also shedding a light on business requirements and highlighting the big expectations from a perfect Mashup solution which can be useful for Mashup vendors. This may help them to get a better outlook of Enterprise 2.0 requirements and to get a step closer to perfect Mashup solutions.

\section{References}

1. Sweeney, S., Craig, R.: Social Media for Business, p. XV (2011) ISBN: 978-1931644914

2. Newman, A., Thomas, J.: Enterprise 2.0 Implementation: Integrate Web 2.0 Services into Your Enterprise. McGraw-Hill, Osborne (2009) ISBN: 978-0071591607

3. O'Reilly, T.: What Is Web 2.0: Design Patterns and Business Models for the Next Generation of Software (2005), http://oreilly.com/web2/archive/whatis-web-20.html (retrieved June 2012)

4. Jeon, S., Kim, S.T., Lee, D.H.: Web 2.0 business models and value creation. International Journal of Information and Decision Sciences 3(1), 70-84 (2011)

5. Vossen, G.: Web 2.0: From a Buzzword to Mainstream Web Reality. In: Obaidat, M.S., Filipe, J. (eds.) ICETE 2009. CCIS, vol. 130, pp. 53-67. Springer, Heidelberg (2011) ISBN: 978-3642200779

6. Büchner, T., Matthes, F., Neubert, C.: Functional Analysis of Enterprise 2.0 Tools: A Services Catalog. In: Fred, A., Dietz, J.L.G., Liu, K., Filipe, J. (eds.) IC3K 2009. CCIS, vol. 128, pp. 351-363. Springer, Heidelberg (2011)

7. McAfee, A.: Enterprise 2.0: New Collaborative Tools for Your Organization's Toughest Challenges. Harvard Business School Press (2009) ISBN: 978-1422125878

8. Hinchcliffe, D.: The state of Enterprise 2.0 (2007), http: / /www. zdnet.com/blog/hinchcliffe/the-state-ofenterprise-20/143 (retrieved April 18, 2011)

9. Schein, E.H.: The corporate culture survival guide. John Wiley \& Sons (2009) ISBN: 9780470293713

10. Thomas, D.B., Barlow, M.: The Executive's Guide to Enterprise Social Media Strategy: How Social Networks Are Radically Transforming Your Business. Wiley and SAS Business Series, p. 43 (2011) ISBN: 978-0470886021

11. Andjomshoaa, A., Bader, G., Tjoa, A.: Exploiting Mashup Architecture in Business Use Cases. In: International Conference on Network-Based Information Systems, Indianapolis, USA, pp. xx-xxvii. IEEE (2009) ISBN: 9780769537672 
12. Becker, A., Widjaja, T., Buxmann, P.: Nutzenpotenziale und Herausforderungen des Einsatzes von Serviceorientierten Architekturen. Ergebnisse Einer Empirischen Untersuchung aus Anwender- und Herstellersicht. Wirtschaftsinformatik (2011), doi: 10.1007/s11576-011-0280-4

13. JackBe Corporation, A Business Guide to Enterprise Mashups (2009), http: / /www.jackbe.com/downloads/jackbe_business_guide_to_ent erprise_mashups.pdf (retreived June 2012)

14. Bader, G., Anjomshoaa, A., Tjoa, A.: Privacy Aspects of Mashup Architecture. In: The Second IEEE International Conference on Information Privacy, Security, Risk and Trust (PASSAT 2010), Minneapolis, Minnesota, USA, pp. 1141-1146 (2010) ISBN: 978-07695-4211-9

15. Lawton, G.: Web 2.0 Creates Security Challenges. Computer 40(10), 13-16 (2007), doi:10.1109/MC.2007.367 (retrieved)

16. Ogrinz, M.: Mashup Patterns, Design and Examples for the Modern Enterprise. AddisonWesley (2009) ISBN: 978-0321579478

17. Tapp, A.: Principles of Direct and Database Marketing: A Digital Orientation, p. 302. Financial Times Prentice Hall (2008) ISBN: 978-0273713029

18. Müller, R.: Project Governance (Fundamentals of Project Management), p. 2. Gower Publishing Ltd. (2009) ISBN: 978-0566088667

19. Pentland, A.S.: Of kith and contentment (2010), http: / /www.psychologytoday.com/blog/realitymining/201004/kith-and-contentment (retrieved June 2012)

20. Spolsky, J.: Strategy Letter IV: Bloatware and the 80/20 Myth - Joel on Software (2001), http: / / www. joelonsoftware.com/articles/fog 0000000020 .html (retrieved June 2012)

21. Lussier, R.N.: Management Fundamentals: Concepts Applications Skill Development, pp. 203-207. South Western Education Publisher (2008) ISBN: 978-0324569643 